\title{
Autosomal recessive spastic paraplegia type 28
}

INSERM

\section{Source}

INSERM. (1999). Orphanet: an online rare disease and orphan drug data base. Autosomal recessive spastic paraplegia type 28. ORPHA:101008

Autosomal recessive spastic paraplegia type 28 is a pure form of hereditary spastic paraplegia characterized by a childhood or adolescent onset of slowly progressive, pure crural muscle spastic paraparesis which manifests with mild lower limb weakness, gait difficulties, extensor plantar responses, and hyperreflexia of lower extremities. Less common manifestations include cerebellar oculomotor disturbance with saccadic eye pursuit, pes cavus and scoliosis. Some patients also present pin and vibration sensory loss in distal legs. 